\title{
Do Accounting Students Believe in Self-Assessment?
}

\author{
Tanya Hill
}

Department of Taxation, University of Pretoria, Pretoria, South Africa

\begin{abstract}
In education, formal assessment focuses on summative assessment with the objective of allocating grades, limiting learning by students. Formative assessment, in the form of self-assessment, has been proposed as beneficial to student learning in various fields. This study explores the perceptions of accounting students of the self-assessment process after exposure to the process on three occasions in a facilitated environment created by their lecturers. The students' perceptions on self-assessment were collected via a structured survey.

It was found that most students did not self-assess unless encouraged to do so. However, once they were exposed to self-assessment in an environment supportive to such assessment, students were positive about the process. After the facilitated process, they believed that self-assessment would improve their overall academic performance and indicated that they would apply self-assessment in future. This research provides insight into accounting students' perceptions of self-assessment in learning, demonstrating the importance of investigating the benefits from a student perspective.
\end{abstract}

Keywords: reflective learning; self-assessment; formative assessment; accounting education; accounting students 


\section{Introduction}

In this study, I investigated whether accounting students at a South African university believe in the benefits of self-assessment, as a form of reflective learning. Students were encouraged to reflect on what they had learned in a formal assessment, such as a class test. Thereafter, they were asked to compare what they had learned in respect of their goals; and finally, they considered what they would like to change in future to improve and ultimately perfect their performance, in line with what Cambra-Fierro and Cambra-Berdún (2007) advocated. Self-assessment is a form of formative assessment which can facilitate continual learning (Donham, 2010; Reynolds, Livingston \& Willson, 2006).

It is important to ascertain whether or not accounting students in a developing country such as South Africa believe in self-assessment, because, although various studies focusing on various disciplines have argued the benefits of self-assessment (Boud \& Associates, 2010; Bourner, 2003; Cambra-Fierro \& Cambra-Berdún, 2007; Larres, Ballantine \& Whittington, 2003; Papadakis, Fragoulis \& Phillips, 2008; Ryan \& Ryan, 2013; Zimmerman, 2002), there is still a lack of evidence showing whether South African accounting students believe that they can benefit from engaging in self-assessment. Some studies have focused on students' ability to self-assess: a study in the USA by Kruger and Dunning (1999), studies in Australia by Langendyk (2006) and Lawson et al. (2012), and a study in South Africa by Peckham and Sutherland (2000). However, there is little evidence on whether South African accounting students believe that the self-assessment process is meaningful. The objective of this study was to fill this gap in the literature.

The objective of this study was to investigate students' perceptions of the selfassessment process once they had been exposed to it for a specific length time in a facilitated environment, allowing them to base their beliefs on their experiences. The research was conducted by encouraging final year undergraduate accounting students at a large South 
African university to self-assess their answers to three of their formal class tests in a one-year Taxation module. The process was facilitated by means of specially designed answer booklets with carbon paper that allowed the students to self-assess their tests and allowed me (as the researcher and one of these students' lecturers) to assess students' answers independently. Thereafter, the students' perceptions regarding the benefits of the three selfassessments were collected via a structured questionnaire at the end of the teaching intervention. The results suggest that this teaching intervention changed students' beliefs on self-assessment, and that after the intervention, they believed that self-assessment is a beneficial process that can help them to improve their academic performance.

This study contributes to the literature by providing insight into South African Accounting students' perceptions of self-assessment in learning, demonstrating the importance of investigating the benefits of this kind of assessment from a student perspective. This fills the gap in literature in terms of whether or not South African Accounting students believe in self-assessment. Students who buy into the process of self-assessment are more likely to apply the technique of self-assessment actively in future. It is also envisaged that this study will assist educators such as lecturers at a tertiary institution in creating an environment which encourages self-assessment and thus stimulate life-long learning for their students through internalization of self-assessment techniques as part of the learning process.

This introduction is followed by the literature review of the study, which looks more closely at the importance of self-assessment and what skills are required to self-assess. The literature review also focuses on how to measure self-assessment and how accurately students are likely to perform this task. The research design and method are then discussed. In the final sections, the results are analyzed and a conclusion is drawn about the study. 


\section{Literature Review}

\subsection{Importance and Benefits of Self-Assessment}

Several studies argue that reflective learning through self-assessment can help to improve students' academic performance (Cambra-Fierro \& Cambra-Berdún, 2007; Zimmerman, 2002) and to develop an awareness of life-long learning (Boud \& Associates, 2010; Bourner, 2003; Larres et al., 2003; Ryan \& Ryan, 2013). Self-assessment promotes self-learning, rather than grade allocation (Lawson et al., 2012). Although students' work needs to be assessed and graded to give feedback to various stakeholders on their academic progress, assessment can also be used effectively to promote sound learning habits. Unlike summative assessment, formative assessment, and more specifically self-assessment, is an active form of learning which encourages students to take responsibility for their own learning (Donham, 2010). It follows a constructivist approach to learning, which requires students and lecturers to be actively involved in the process (Lawson et al., 2012). Students who are actively engaged in the self-assessment process are encouraged to learn in a proactive and adaptive manner. The process develops self-regulated, critical students who can make good judgments and are more likely to succeed academically (Zimmerman, 2002).

Self-assessment is an economical teaching tool with educational benefits, and should be used more widely by lecturers - it has been argued that it is not always necessary for lecturers to give feedback to students, as students can often learn more by assessing themselves or from a peer-assessment process (Ramsden, 2003). Self-assessment can also act as an earlywarning system for students who underperform, and it effectively moderates students' expectations, which are often unrealistically high (Peckham \& Sutherland, 2000).

Despite all these benefits of self-assessment, it has often seemed to me in my experience as a lecturer at a South African university that my students are only interested in 
the grade they receive for a test or assignment, and do not self-assess or reflect on what they have done - once they have received a grade, they simply move on. My discussions with colleagues in accounting-related subjects such as Auditing and Finance suggest that my experience is not an isolated case. If that is indeed the case, the students miss out on using what they have done in the test or assignment as a powerful reflective tool and learning opportunity. However, if students believed that self-assessment is beneficial to them, they would be more likely to implement it. This suggests that exposure to self-assessment could positively affect students' belief in the process.

\subsection{Applying Meaningful Self-Assessment}

Prior research suggests that students require certain skills to apply meaningful selfassessment. Firstly, students need metacognitive awareness in order for them to self-regulate (Cassidy, 2006; Zimmerman, 2002). Low-achieving students generally lack the skills of metacognition and self-monitoring that they need to know and measure how they are performing; therefore they tend to over-estimate their ability (Christensen, Fogarty \& Wallace, 2002; Kruger \& Dunning, 1999; Larres et al., 2003). Sangster and McCombie (1993) also found that, at the start of their studies, first-year students tend to be overconfident and to over-estimate their ability, as opposed to second-year students who have more experience of the tertiary environment.

Cassidy (2006) classifies a student's learning style as either deep or surface learning. He argues that a student's specific learning style is also critical to self-assessment, and that deep strategic learners are better equipped to self-assess than apathetic students.

In addition to the required skills, commitment and willingness are two key attributes that students need to develop the skill of self-assessment (Cambra-Fierro and CambraBerdún, 2007). However, commitment and willingness will probably increase over time if the 
learning environment encourages self-assessment and students begin to see the benefits for themselves. Therefore, it is important for students to have more than one experience of selfassessment.

Once students have applied self-assessment, it is important to determine how accurate and meaningful the process was. It is difficult to measure how well a student has assessed him-/herself and reflected on the learning, as only the student who has reflected can evaluate how meaningful the process was for him/her. Previous studies have investigated how closely students' self-assessed grades correlated with the formal grades awarded by their lecturers as an indicator of how accurately students carried out the self-assessment, but these studies did not consider if students found the process meaningful (Kruger \& Dunning, 1999; Langendyk, 2006; Lawson et al., 2012).

Kruger and Dunning (1999) conducted a study in the United States with four different sets of undergraduate psychology and human development students. The students completed a written assessment and then were asked to assess their own perceived performance. Results for all four groups showed that low-achieving students over-estimated their skills and abilities. They lacked the skill of metacognition which would enable them to determine how poorly they have performed, and therefore they held an inflated view of their performance and ability.

A smaller study was carried out in South Africa by Peckham and Sutherland (2000) with ten first-year chemistry students. The students' expectations were evaluated before an assessment. These expectations were then compared with a self-assessment completed by the students after the actual assessment, as well as with the final grade awarded by the lecturers. A strong correlation was found between the self-assessment grades and the formal grades awarded by the lecturers (Peckham \& Sutherland, 2000). 
In a similar study carried out by Langendyk (2006) in Australia, third-year medical students were asked to self-assess their own written assessments, based on model answers and detailed marking criteria. Each student was then also required to mark a fellow student's assessment. Thereafter, the assessments were formally marked by their lecturers. The results of the study showed that low-achieving students were generally generous in awarding themselves marks, whereas high-achieving students were very critical and marked themselves harshly. Langendyk (2006) concluded that students who are unsuccessful in their academic studies are often unable to assess the level of their own performance.

A recent study by Lawson et al. (2012) in Australia gave second-year economics students four consecutive opportunities to self-assess. On each occasion, each student's selfassessment grade was compared with the lecturer's grade. It was found that students improved their self-assessment technique through support during the process and progressive exposure to self-assessment (Lawson et al., 2012).

Various studies on students in different disciplines and countries have shown the benefits or theoretical value of self-assessment, but studies also show that the accuracy of self-assessment among students is poor. A possible solution to this problem is providing explicit evaluation criteria that students can use to assess their work (Larres et al., 2003; Ward, Gruppen \& Regehr, 2002). Peckham and Sutherland (2000) also believe that students are able to self-assess more accurately if they are provided with sufficient guidance.

\subsection{Promoting an Environment of Self-Assessment}

According to Zimmerman (2002), few lecturers encourage their students to set goals for their studies or encourage different methods of study; students are also seldom asked to selfassess their progress. Students need encouragement and guidance to self-assess in order for them to engage fully in the process, so lecturers should provide this guidance and 
encouragement (Cambra-Fierro \& Cambra-Berdún, 2007). By encouraging the development of self-assessment, lecturers can assist students to develop from being dependent on others to taking responsibility for their own continual learning.

Students should be allowed numerous opportunities to practice self-assessment - in Lawson et al.'s (2012) study, the majority of students who have been given the opportunity to self-assess would prefer to be given the opportunity again in future. This research suggests it is important to self-assess on more than one occasion by creating an environment of selfassessment which encourages students to develop the skill.

\section{Aim}

The aim of this empirical study was to use a teaching intervention to facilitate selfassessment among a group of South African accounting students, and then to discover by means of a survey whether this group of students did practice self-assessment prior to being explicitly encouraged to do so, and whether the intervention (creating an environment conducive to self-assessment) had changed their beliefs regarding self-assessment.

\section{Method}

\subsection{Sample}

The target population for this study was all final-year undergraduate accounting students at a large South African university who were registered for the third-year Taxation module in the 2012 academic year. The students in this module were used as a convenience sample for this study because my involvement in this module gave me access to the research subjects. The one-year Taxation module was one of these students' majors. The Faculty of Economic and Management Sciences' database on the date on which the survey was distributed listed 561 students who were registered for the module. 


\subsection{Step 1: The Teaching Intervention}

The intervention was implemented for all 561 registered students. During the course of the 2012 academic year, the students wrote six class tests which collectively contributed $10 \%$ to the students' final marks for the module. The intervention was conducted using three of these six tests. These three tests were chosen because they are more 'objective-based' and more amendable to self-assessment. ${ }^{1}$

In order to encourage participation in the intervention, a self-assessment assignment, which counted $5 \%$ toward the final grade for the module, was developed. The total selfassessment assignment was out of 150 marks and was spread across the three class tests used in the intervention. Each of the three self-assessments represented a sub-assignment and contributed 50 marks to the 150 marks of the total assignment. For the self-assessment assignment, marks were awarded using a sliding scale based on how accurately students assessed themselves for each of the three class tests relative to the marks awarded by their lecturers. $^{2}$ I believe that this provided an incentive to the students to engage with the intervention seriously, without a material impact on their final grade. Although this incentive was offered to students to take part in the intervention, no incentive was offered to encourage participation in the survey.

The details of the intervention were explained to the students in one of their formal lectures prior to being implemented. During this discussion, I (as one the students' lecturers)

\footnotetext{
${ }^{1}$ This intervention was the first time that many of the students were called upon to engage in self-assessment, so I chose calculation-based questions rather than discussion questions as an introduction to self-assessment. I wanted to make the results of the three sub-assignments comparable, so I used similar calculation-based questions in all three class tests. These calculation questions are not simple "right or wrong" answers, because they are integrated, test various principles and contain multiple steps. Lecturers often emphasize to students that it is not about the final answer of the calculation, but the thought process going into each of the individual steps. It would not have been possible for students to score a high mark on the accuracy of self-assessment, unless they made a concerted effort to follow all the steps of each calculation through to their final answer.

${ }^{2}$ Marks were also allocated for reflection questions, which counted $20 \%$ of each sub-assignment. The remaining $80 \%$ was allocated for the accuracy of the self-assessment.
} 
encouraged the students to participate in the intervention by explaining how self-assessment could be beneficial to their studies. As this intervention was specifically designed as an experiential learning experience, I did not provide any further information on self-assessment or on the possibility that students' might over-estimate their ability, as I did not want to impose my ideas on the students or bias the outcome of the results.

The intervention was designed to create an environment which encouraged selfassessment. Instead of the students' writing their class tests in the university's standard preprinted answer books, new loose-page sets were designed and printed for these three tests. These loose-page sets, printed on self-carbon paper, were made up of two pages each and were bound with glue at the top. The front page, on which the students completed their answers, was white and had lines pre-printed on it. The second page was yellow, and the selfcarbon set ensured that students were left with a copy of their test answers on this yellow page. At the end of each class test, students were given time to separate the white from the yellow sheets and to collate the white sheets before handing them in for marking. The students then kept the yellow sheets in order to assess themselves at home based on what they had done in their tests. In Peckham and Sutherland's (2000) much smaller South African study, students' tests were photocopied and the copied assessments were returned to the students. Due to the large number of students in the module (561 students), I developed the self-carbon sets to facilitate the roll-out of the intervention.

Before the end of the same day on which the class test was written, students were provided with a model answer to the test, as well as a detailed marking plan, on the university's online learning management system (ClickUp). Tests for the module contain predominantly calculation-based questions requiring minimal discussion, and it was therefore easy to provide a structured marking memorandum. Students were given an opportunity to manually self-assess their answers to the class test, and were required to submit their own 
self-assessment mark electronically on ClickUp. The students were also asked reflective questions via ClickUp, which encouraged them to focus on the positive and negative aspects of their class test.

\subsection{Step 2: The Survey}

In order to address the objective of this study, I developed a structured survey. ${ }^{3}$ Of the 11 questions used in the survey, ten were closed-ended, using a 5-point Likert type scale, and one was open-ended, which allowed students to comment on their perceptions of selfassessment in their own words. This was the only question which provided qualitative information for the study. The survey was previewed by an independent research consultant to limit the possibility of misinterpretation of the questions. To establish face validity, a pilot study was also carried out with five senior lecturers in the Taxation department, who critically evaluated the survey. Their suggestions were incorporated into the final instrument.

Students were given the opportunity to complete the survey on a voluntary basis during one of their formal lectures. ${ }^{4}$ A total of 282 completed surveys were collected, which represents a 50\% response rate. Of the respondents $(n=282), 181(64 \%)$ were female and 101 $(36 \%)$ of the respondents were male. Of the respondents $(n=282), 191(68 \%)$ of the respondents were studying the module in their home language, while 91 (32\%) were not.

\subsection{Data Analysis}

The closed-ended questions provided response options which were mutually exclusive, in order to facilitate coding. These responses were captured, and the data were then analyzed

\footnotetext{
${ }^{3}$ Ethical clearance was obtained from the Research Ethics Committee of the Faculty prior to the distribution of the survey.

${ }^{4}$ A limitation of this method is that students who did not attend the class did not have an opportunity to complete the survey. However, since class attendance is compulsory, I did not feel obligated to create an additional opportunity for data collection.
} 
by frequency. I summarized and analyzed the data from the open-ended qualitative question to identify themes that recurred frequently in the data.

\section{Results}

\subsection{Student Self-Assessment Prior to the Implementation of the Teaching Intervention}

In the survey, respondents were asked what they did with marked tests or assignments (prior to the intervention) when they received them back from their lecturers. The mutually exclusive response options as well as the frequency distribution for this question are summarized in Table 1.

Self-assessment or reflective learning involves something more than simply checking the adding up of marks or quickly scanning through a marked assessment. I therefore considered only the last two of the five response options which respondents had to choose from (see Table 1), as reflecting a form of self-assessment:

- 'Scan through the assessment and review questions that I did badly in' (15.9\%); or

- 'Work through the entire assessment in detail' (7.2\%).

Therefore, based on the responses, it seems that prior to the implementation of the intervention, only $23.1 \%$ of the respondents engaged in some form of meaningful selfassessment, and the other $76.9 \%$ did not self-assess meaningfully at all.

\subsection{Building Self-Assessment Habits}

To determine whether students would continue to self-assess in the absence of an environment which encourages it, the survey asked the respondents what they would do in future when they received back marked tests from their lecturers.

The data collected from this question was compared with the data collected from the question which looked at what the respondents did with their assessments prior to the 
implementation of the intervention. The options available for these two questions were identical. A frequency procedure and cross-tabulation was used to compare the data from the two questions and these findings are summarized in Table 1.

Table 1. Level of Self-Assessment Prior To and After the Intervention

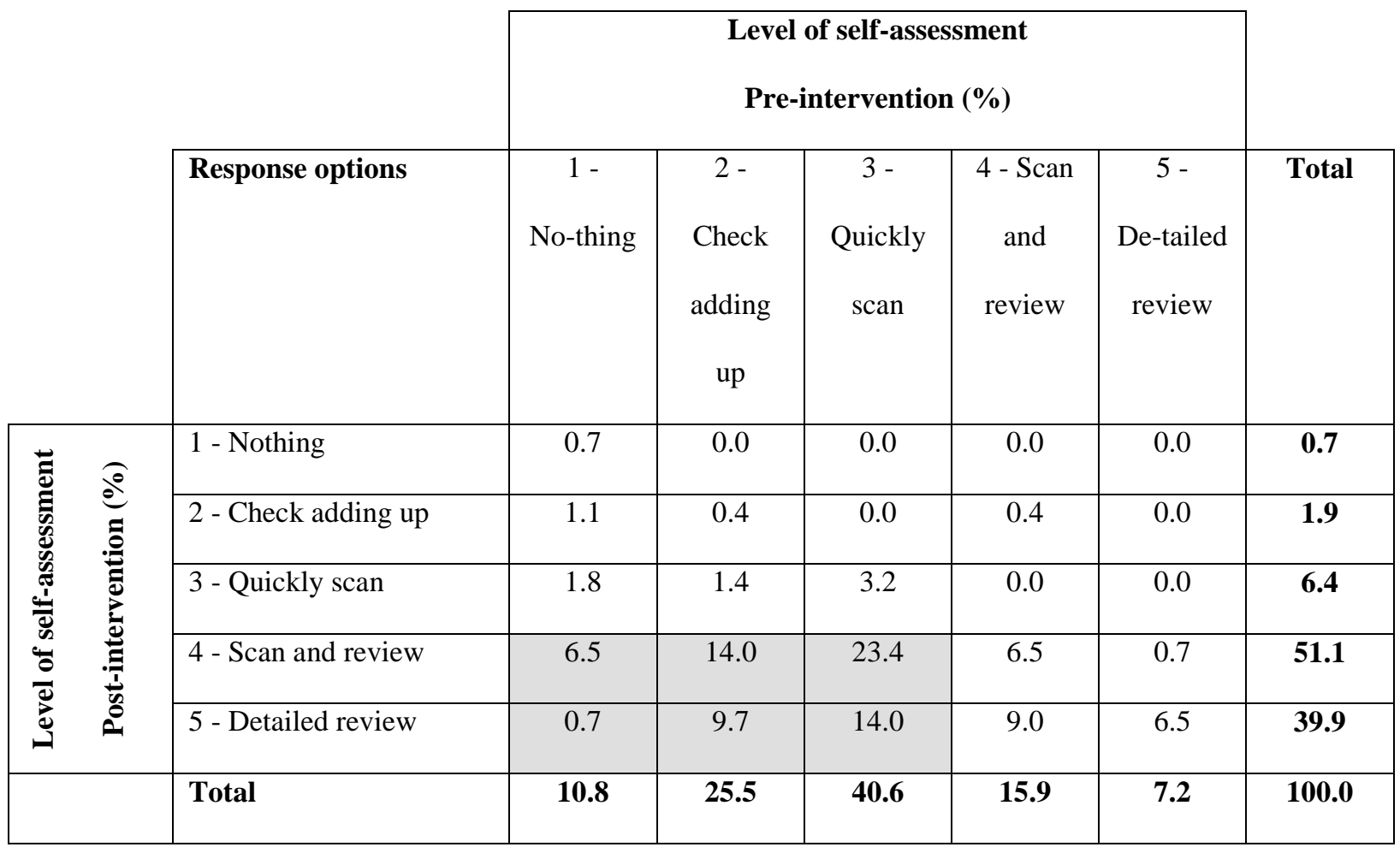

It is clear from the above table that respondents would be more inclined to self-assess after the intervention even if they were not encouraged to do so. Previously, it was stated that only the respondents who chose one of the following two options were involved in a form of self-assessment:

- 'Scan through the assessment and review questions that I did badly in'; or

- 'Work through the entire assessment in detail'.

The data clearly show that $51.1 \%$ (post-intervention) versus $15.9 \%$ (pre-intervention) of the respondents would scan through their marked work and review questions they had done 
badly in; and 39.9\% (post-intervention) versus $7.2 \%$ (pre-intervention) of the respondents would work through their assessments in detail.

Therefore, prior to the implementation of the intervention, only $23.1 \%$ of the respondents were engaged in some form of self-assessment, compared to $91.0 \%$ of the respondents who said they would self-assess after the intervention. Table 1 shows that $68.3 \%$ (sum of shaded cells) did not engage in meaningful self-assessment prior to the intervention, but will do so afterwards. This evidence supports the notion that a self-assessment intervention could be effective in changing students' negative perceptions about selfassessment. Therefore, it can be concluded that students who were exposed to the teaching intervention would probably continue to self-assess in future, even in the absence of an environment that encouraged it.

\subsection{Students' Perceptions about Self-Assessment after Exposure to the Process}

To determine what students' perceptions towards self-assessment were once they had been exposed to it on three occasions, respondents were asked in the survey how they felt about self-assessment prior to and after having been exposed to it. The only factors that changed for the students was the lecturer placing emphasis on self-assessment and the grade incentive offered to students for participating in the intervention. The results of the frequency distribution as well as a cross-tabulation of both questions are summarized in Table 2. 
Table 2. Respondents' Perceptions of a Self-Assessment Environment

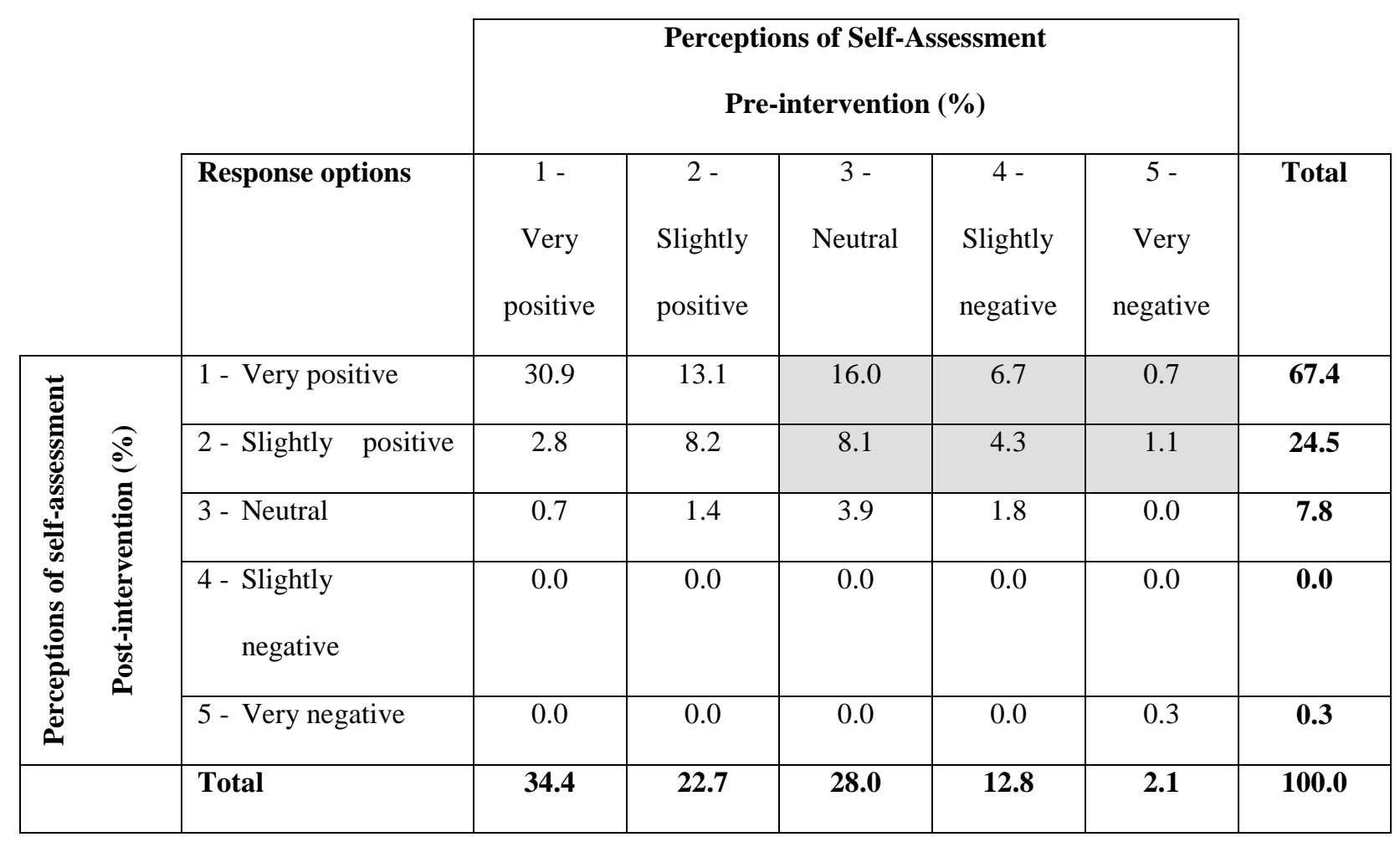

It is clear from the above table that the respondents were more positive about selfassessment after being exposed to the self-assessment intervention. This is important as this study focused on students' beliefs or perceptions on self-assessment and how this changed once they were exposed to it. Prior to the intervention, only $57.1 \%$ of the respondents were positive (34.4\% were very positive and $22.7 \%$ were slightly positive). Although $57.1 \%$ of the respondents were positive about self-assessment prior to the intervention, only $23.1 \%$ actually engaged in self-assessment (see discussion in 5.1 above). This suggests that the claim by $57.1 \%$ of the respondents in response to the questionnaire was not aligned with students' actual practices. After the intervention, $91.9 \%$ of the respondents were positive (67.4\% were very positive and $24.5 \%$ were slightly positive).

A paired t-test was used to compare the respondents' perception of a self-assessment environment before and after being exposed to it. These results were significant (t-value: 
12.76; p-value: <0.0001). This shows a definite increase in the positivity of the respondents towards self-assessment once they had been exposed to an environment that encouraged it.

The cross-tabulation in Table 2 shows that $36.9 \%$ (sum of shaded cells) of respondents who were neutral, slightly negative or very negative prior to the intervention, were very positive or slightly positive about self-assessment after the intervention. This evidence suggests that the intervention affected the perceptions of students most negative about selfassessment.

The respondents were next asked if they would like the self-carbon self-assessment environment to be applied in future assessments. A frequency distribution was used to analyze the data from this question. Of the 282 respondents, $67.4 \%$ would like the selfassessment environment to be applied in future assessments, $28.7 \%$ are not sure and only $3.9 \%$ would not like to have it applied in future. This data correlates with the data from the question which tested the positivity of the respondents after being exposed to the selfassessment environment (see Table 2). In both instances, $67.4 \%$ of the respondents were very positive about the self-assessment environment.

Therefore, it can be concluded that students are positive about a facilitated selfassessment environment and would appreciate it if a suitable environment is created for future assessments in their studies.

The survey asked respondents (once they had been given the opportunity to self-assess) whether, now that they had had an opportunity to self-assess with the carbon copies, they found self-assessment beneficial in terms of its improving their academic performance. A frequency distribution was used to analyze the data from the question. A cross-tabulation of this question, together with how students perceived self-assessment prior to the intervention is summarized in Table 3. 
Table 3. Did Respondents Believe that Self-Assessment Improved Their Academic Performance?

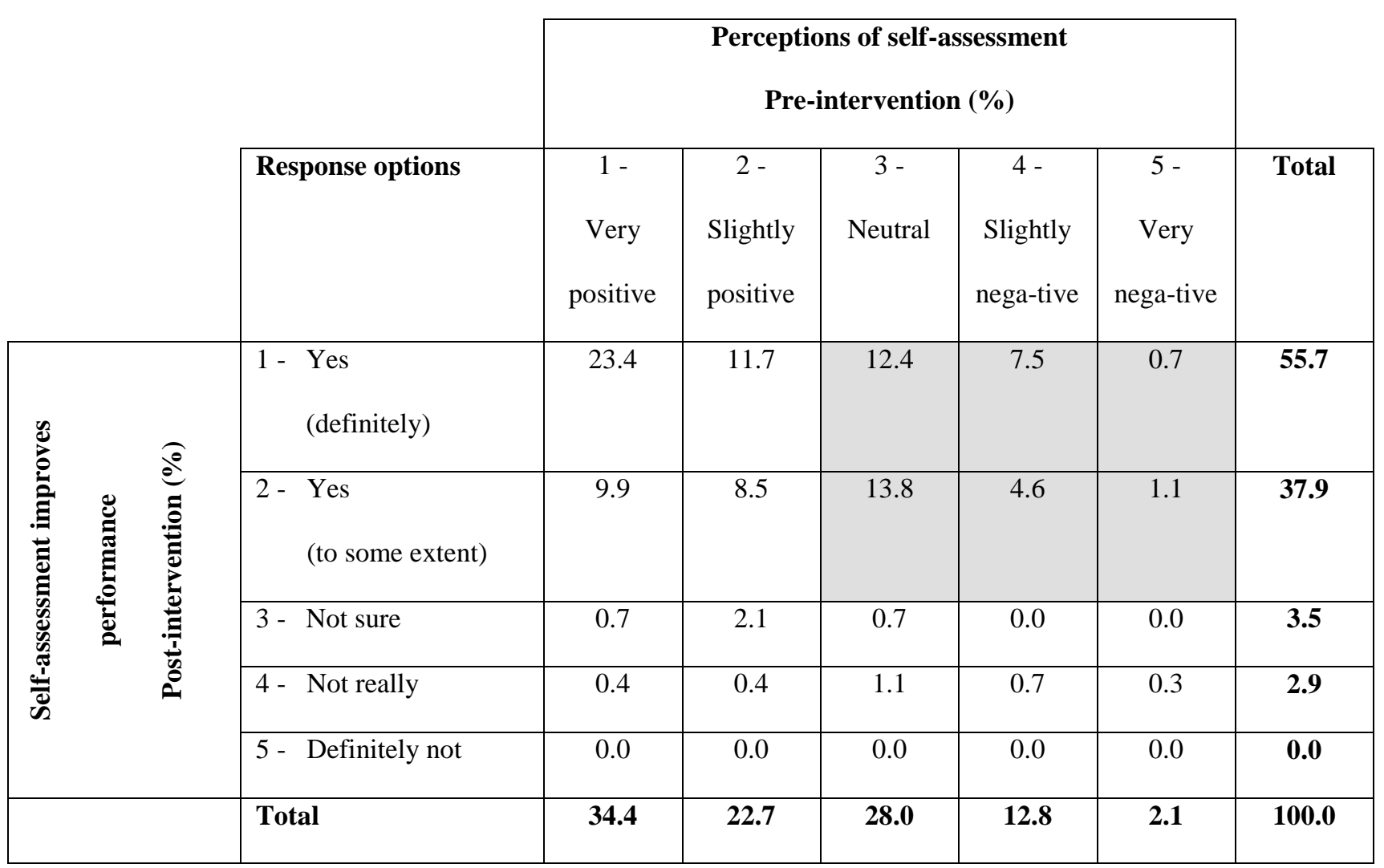

Table 3 shows that $40.1 \%$ (sum of shaded cells) of respondents were neutral, slightly negative or very negative about self-assessment prior to the intervention, but believed that self-assessment could improve their academic performance (definitely or to some extent) after being exposed to self-assessment. This evidence suggests that the self-assessment intervention has been successful in changing the perceptions of these respondents. Of the respondents, 93.6\% (55.7\% "Yes (definitely)" and 37.9\% "Yes (to some extent)") believed that self-assessment was beneficial to their academic performance to some degree, and that it can ultimately improve their academic performance.

The final question of the survey was open-ended and respondents were given the opportunity to make any further comments on the self-assessment intervention. A total of 202 respondents made use of the opportunity to provide additional comments. I only summarized the data relevant to self-assessment being beneficial. After analyzing these comments, I 
identified frequently recurring themes regarding the additional benefits of self-assessment. These additional benefits, as well as the frequency with which they were mentioned in the responses to the open-ended question, are set out in Table 4.

Table 4. Additional Benefits of Self-Assessment Identified by Respondents

\begin{tabular}{|l|c|}
\hline Benefit of Self-Assessment & Frequency \\
& (n= 202) \\
\hline Improved examination technique & 50 \\
\hline Ability to identify errors and problem areas which need to be worked on & 25 \\
\hline Information still fresh in mind and ability to deal with issues immediately & 6 \\
\hline Improved marks & 6 \\
\hline Encouraged to review assessments & 6 \\
\hline$\underline{\text { Key: }}$ & \\
\hline This table reports the frequency of students who made comments regarding the following themes.
\end{tabular}

A central message is that students understanding of self-assessment improved as a result of experiential learning through the teaching intervention. Some of the specific comments made by the students suggested that they felt that self-assessment would specifically improve their examination technique by helping to improve the layout of their answers in future tests and examinations; it gave them insight into how to answer in a more structured manner; it helped to structure answers in tests in such a way that they were easier to mark by their lecturers; it helped them to understand how marks are awarded in an assessment and thereby ensure they obtain the maximum marks possible in future tests; and it also helped in students' understanding of how much detail to provide when answering a question. 
Based on the above results, it can be concluded that students do find self-assessment beneficial, and among other benefits, believe that it could ultimately improve their academic performance.

\subsection{Willingness to Engage in Accurate and Meaningful Self-Assessment in a Supportive}

\section{Environment}

To determine whether students were encouraged to apply self-assessment in the environment created by the intervention, I compared the number of students who wrote each of the formal tests with the number of students who submitted the self-assessment subassignment. A total of 561 students wrote the Class Test 1, of whom 535 (95.4\%) also did the self-assessment sub-assignment. Class Test 2 was also written by 561 students, of whom 540 (96.3\%) did the self-assessment sub-assignment, and Class Test 3 was written by 545 students, of whom $523(96 \%)$ did the self-assessment sub-assignment. The high percentage of students who did perform self-assessment suggests that students are encouraged to self-assess in an environment which supports it. While it is difficult to attribute the high submission rates to a specific factor, I would argue that it is the combination of the grade incentive and the emphasis placed by myself on self-assessment during formal lectures which contributed to the high self-assessment assignment submissions. Previous studies have considered whether students can self-assess accurately (Kruger \& Dunning, 1999; Langendyk, 2006; Lawson et al., 2012; Peckham \& Sutherland, 2000), but none of these studies encouraged the students to self-assess by offering a grade incentive.

However, the question remains whether or not students engaged in their self-assessment at least partially to obtain some benefit from the learning experience. To encourage students to undertake meaningful self-assessment, marks were awarded for the accuracy of their selfassessment (see 4.2 above). I divided the students into quartiles per class test based on the 
formal marks awarded by the lecturers. I then evaluated the average differences per class test for each quartile between the students' self-assessed marks and the formal marks awarded by the lecturers. These findings are summarized in Table 5.

Table 5. Accuracy of Self-Assessment

\begin{tabular}{|c|c|c|c|c|}
\cline { 2 - 5 } \multicolumn{1}{c|}{} & \multicolumn{3}{c|}{ Quartiles of Lecturers' Marks } \\
\hline Average mark & $\mathbf{1}^{\text {st }}$ quartile (\%) & $\mathbf{2}^{\text {nd }}$ quartile (\%) & $\mathbf{3}^{\text {rd }}$ quartile (\%) & $\mathbf{4}^{\text {th }}$ quartile (\%) \\
\hline Class Test 1 & 44.7 & 60.1 & 70.0 & 81.1 \\
Lecturers & 45.0 & 57.8 & 67.0 & 77.0 \\
Students & 42.8 & 57.5 & 65.7 & 75.3 \\
\hline Class Test 2 & 45.4 & 57.7 & 64.5 & 72.6 \\
Lecturers & & & & \\
Students & 35.3 & 50.4 & 61.2 & 69.4 \\
\hline Class Test 3 & 35.1 & 47.6 & 57.1 & \\
\hline Lecturers & & & & \\
\hline Students & & & & \\
\hline
\end{tabular}

The students in the first quartile tended to over-estimate their abilities. This is in line with what Kruger and Dunning (1999) and Langendyk (2006) found. This over-estimation and the accuracy of self-assessment of the students in the first quartile improved from Class Test 1 to Class Test 3. This improvement in self-assessment technique over time corresponds to Lawson et al.'s (2012) study.

As can be seen from Table 5, on average, students appeared to be able to apply accurate self-assessment and the average difference across the three assessments ranged from $0.2 \%$ to 6.1\%. The $6.1 \%$ difference relates to the top achieving students (quartile 4) in Class Test 3. 
The top achieving students were generally more critical (conservative) in their selfassessment. This may not be an accurate reflection of their ability to self-assess, but rather a specific personality trait. This is consistent with Langendyk (2006).

The results suggest that students can apply accurate and meaningful self-assessment.

\section{Additional analysis}

A concern with a response rate of $50 \%$ is the possibility of non-response bias: it is possible that students did not complete the survey because they did not attend class on the day when it was administered, they were not interested in completing a survey or they were negative or indifferent to the self-assessment intervention. Table 6 investigates the issue of non-response bias further.

Table 6. Non-response bias

\begin{tabular}{|c|c|c|c|c|}
\hline & \multicolumn{2}{|c|}{ Respondents } & \multicolumn{2}{|c|}{ Non-respondents } \\
\hline & Mean (\%) & $\mathbf{n}$ & Mean (\%) & $\mathbf{n}$ \\
\hline Class Test 1 & & & & \\
\hline Lecturers & 65.9 & 272 & 60.9 & 289 \\
\hline Students & 63.5 & 268 & 59.6 & 267 \\
\hline$\%$ assignment submission & & $98.5 \%$ & & $92.4 \%$ \\
\hline Class Test 2 & & & & \\
\hline Lecturers & 61.6 & 275 & 57.9 & 286 \\
\hline Students & 60.9 & 272 & 58.7 & 268 \\
\hline$\%$ assignment submission & & $98.9 \%$ & & $93.7 \%$ \\
\hline Class Test 3 & & & & \\
\hline Lecturers & 57.5 & 270 & 53.4 & 275 \\
\hline Students & 54.3 & 265 & 50.7 & 258 \\
\hline$\%$ assignment submission & & $98.1 \%$ & & $93.8 \%$ \\
\hline
\end{tabular}


The data indicates that on average, the respondents perform slightly better in their assessments than the non-respondents. It also indicates that on average, the accuracy of selfassessment between respondents and non-respondents is very similar. On average nonrespondents were slightly lower on the uptake of completing the self-assessment subassignments, but the uptake was still high. This suggests that the effect of any non-response bias is minor.

\section{Conclusion}

The aim of this study was to determine, by means of a teaching intervention and a structured survey, accounting students at a South African university's perceptions of a selfassessment process once they had been exposed to it over three class tests in a year in a facilitated environment. The main questions considered were whether students self-assessed prior to the implementation of the teaching intervention, as well as whether they could be encouraged to apply accurate and meaningful self-assessment in an environment which supported it. The study also investigated the value students attached to the process and whether or not they believed it would improve their overall academic performance. Furthermore, the study determined whether or not they believed they would continue using self-assessment as a tool even if an environment of self-assessment was not created by their lecturers in future.

Based on the findings of the survey, this study concludes that students tended not to self-assess if they were not encouraged to do so. However, once given the opportunity to do so through experiential learning, students were positive about the process of self-assessment. They believed that it is a beneficial process which will ultimately improve their academic performance. The results also show that students did apply accurate and meaningful selfassessment in an environment which supported it. Furthermore, students claimed that they 
would continue to apply self-assessment in their studies once they had been exposed to it, even if an environment no longer existed which would encourage it.

While prior studies have focused mainly on self-assessment in the scientific and psychology fields, this study is the first to investigate whether accounting students' perceptions about self-assessment change after an experiential self-assessment intervention (Kruger \& Dunning, 1999; Langendyk, 2006; Peckham and Sutherland, 2000). This study also adds to the existing body of knowledge on the benefits of self-assessment. Unlike most previous studies which tended to focus on the theoretical value of self-assessment, this study focused on a practical environment which encouraged self-assessment and how students perceived this.

The findings of this study are of interest to academic lecturers, especially accounting lecturers at a tertiary level, who wish to create an environment which encourages selfassessment by students. This, in turn, may expose students to self-assessment in a facilitated environment and may allow them to determine whether self-assessment is beneficial to their individual continual learning. It will hopefully also encourage students to utilize this beneficial technique in future, to improve their overall academic performance and ultimately to develop their life-long learning skills.

The study has some limitations. A possible weakness of the design of the teaching intervention is that a control group was not used. However, I believe that this did not significantly affect the main findings, because the focus was on understanding students' perceptions about self-assessment and not to monitor actual changes in academic performance. The intervention was not preceded by a survey of students' beliefs of selfassessment. This was addressed retrospectively in the survey. Future research should take these weaknesses into account. 
Future research could focus on the effect of self-assessment on students' actual academic performance. Future studies could also investigate the effect of peer-assessment using a similar teaching intervention as this study.

This study fills a gap in literature in terms of whether or not South African Accounting students believe in self-assessment. It is envisaged that this study will assist lecturers in creating an environment which encourages self-assessment and, in turn, stimulate life-long learning for their students who may internalize self-assessment techniques as part of the learning process.

\section{References}

Boud, D. \& Associates. (2010) Assessment 2020: Seven propositions for assessment reform in higher education. Sydney: Australian Learning and Teaching Council.

Bourner, T. (2003). Assessing reflective learning. Education and Training, 45(4/5), 267-272.

Cambra-Fierro, J., \& Cambra-Berdún, J. (2007). Students' self-evaluation and reflection (Part 2): An empirical study. Education and Training, 49(2), 103-111.

Cassidy, S. (2006). Learning style and student self-assessment skill. Education and Training, 48(2/3), $170-177$.

Christensen, T. E., Fogarty, T. J., \& Wallace, W. A. (2002). The association between the directional accuracy of self-efficacy and Accounting course performance. Issues in Accounting Education, $17(1), 1-26$.

Donham, J. (2010). Creating personal learning through self assessment. Teacher Librarian, 37(3), 1421.

Kruger, J., \& Dunning, D. (1999). Unskilled and unaware of it: How difficulties in recognizing one's own incompetence lead to inflated self-assessments. Journal of Personality and Social Psychology, 77(6), 1121-1134. 
Langendyk, V. (2006). Not knowing that they do not know: Self-assessment accuracy of third-year medical students. Medical Education, 40, 173-179.

Larres, P. M., Ballantine, J., \& Whittington, M. (2003). Evaluating the validity of self-assessment: Measuring computer literacy among entry-level undergraduates within Accounting degree programmes at two UK universities. Accounting Education: An International Journal, 12(2), $97-112$.

Lawson, R. J., Taylor, T. L., Thompson, G. D., Simpson, L., Freeman, M., Treleaven, L., \& Rohde, F. (2012). Engaging with graduate attributes through encouraging accurate student selfassessment. Asian Social Science, 8(4), 3-12.

Papadakis, S., Fragoulis, I., \& Phillips, N. (2008). The contribution of self-evaluation exercises in blended adult education. Training and Management Development Methods, 22(3), 325-338.

Peckham, G., \& Sutherland, L. (2000). The role of self-assessment in moderating students' expectations. South African Journal for Higher Education, 14(1), 75-78.

Ramsden, P. (2003). Learning to teach in higher education. London: Routledge.

Reynolds, C., Livingston, R., \& Willson, V. (2006). Measurement and assessment in education. Boston, MA: Pearson Education.

Ryan, M., \& Ryan, M. (2013). Theorising a model for teaching and assessing reflective learning in higher education. Higher Education Research \& Development, 32(2), 244-257.

Sangster, A., \& McCombie, I. (1993). How well do Accountancy students understand a set of accounts? Accounting Education, 2(1), 53-70.

Ward, M., Gruppen, L., \& Regehr, G. (2002). Measuring self-assessment: Current state of the art. Advances in Health Sciences Education, 7, 63-80.

Zimmerman, B. J. (2002). Becoming a self-regulated learner: An overview. Theory into Practice, 41(2), 64-70. 